This is an electronic reprint of the original article. This reprint may differ from the original in pagination and typographic detail.

Please cite the original version: Van Ginkel, S, Ruiz, D, Mononen, A, Karaman, C, de Keijzer, A, Sitthiworachart, J. The impact of computer-mediated immediate feedback on developing oral presentation skills: An exploratory study in virtual reality. J Comput Assist Learn. 2020; 1- 11.

DOI: 10.1111/jcal.12424

URL: https://doi.org/10.1111/jcal.12424

This is the peer reviewed version of the following article: Van Ginkel, S, Ruiz, D, Mononen, A, Karaman, C, de Keijzer, A, Sitthiworachart, J. The impact of computer-mediated immediate feedback on developing oral presentation skills: An exploratory study in virtual reality. J Comput Assist Learn. 2020; 1 - 11., which has been published in final form at https://doi.org/10.1111/ical.12424. This article may be used for non-commercial purposes in accordance with Wiley Terms and Conditions for Use of Self-Archived Versions. 


\section{Journal of Computer Assisted Learning}

The impact of immediate feedback on developing oral presentation skills: an exploratory study in Virtual Reality

\begin{tabular}{|r|l|}
\hline Journal: & Journal of Computer Assisted Learning \\
\hline Manuscript ID & JCAL-19-261 \\
\hline Manuscript Type: & Article \\
\hline Technology and Tools: & Virtual/3D Environments \\
\hline Learning process / Pedagogy: & Experiential Learning, Individual learning \\
\hline Paradigm: & Constructivism, Student-Centred \\
\hline Level of education: & Undergraduate \\
\hline Place of learning: & Formal Learning \\
\hline Type of research: & Mixed methods \\
\hline Research technique: & Experimental, Case Study \\
\hline Analysis/evaluation paradigm: & Participatory Evaluation \\
\hline Issues: & Skills, Satisfaction \\
\hline & \\
\hline
\end{tabular}




\title{
The impact of immediate feedback on developing oral presentation skills: an exploratory study in virtual reality
}

\begin{abstract}
Feedback plays a central role in learning. Crucial to this is the nature and timing of the feedback. A number of studies have advocated for immediate feedback having the greater potential to influence learning outcomes. However, alternative studies have challenged this and highlighted that delayed feedback is perhaps preferable, especially when calling for more in-depth cognitive processing. This experimental study explores these two types within a Virtual Reality (VR) environment designed to facilitate the development of pre-university students' presentation skills. Participants were divided across two feedback conditions: immediate and delayed. Results showed that students in both groups made significant development in all presentation criteria across the two-week programme. Further, students perceived the environment to be an effective and motivating platform in which to practise their presentation skills. These findings are crucial as educators seek viable alternatives to provide for and enhance learning beyond the traditional confines of the classroom.
\end{abstract}

Keywords: Presentation skills; Timing of feedback; Virtual reality; Secondary education 


\section{Context for the study}

Presenting is frequently considered as one of the core competencies for higher-educated professionals (e.g. Hinton \& Kramer, 1998; Kerby \& Romine, 2009; Smith \& Sodano, 2011). The ability to present in public is often essential for career success and for effective participation in democratic societies (e.g. Bower, Cavanagh, Moloney, \& Dao, 2011; De Grez, Valcke \& Roozen, 2009; Reitmeier \& Vrchota, 2009). However, young professionals often fail to show effective presentation behaviour in working or educational environments (Chan, 2011). This failure may partly stem from and reflect deficiencies in knowledge or preparedness.

Considering its importance, many educational programmes have dedicated modules to ensure students have the requisite knowledge and practical experience to deliver effective presentations. This is especially the case in pre-university programmes. Within this field, students, as part of their programme, often follow a syllabus dedicated to helping them prepare to present their work to an academic audience. These programmes will often include input and discussion around questions pertaining to what makes a good presentation, how a presentation should be structured and the type of information that should be included. However, in exploring these questions, greater focus is often placed on content over delivery, resulting in students producing work that is information heavy with insufficient attention given to impact on an audience (Robinson, 2015). A study by Januin and Stephen (2015) highlighted this point in stressing that paralinguistic features of delivery, such as voice projection, pace and eye contact, are crucial elements that potentially do not receive enough attention within presentation courses.

The crux of this issue arguably lies in the inherent complexity and sheer number of skills required to present within an academic setting. Along with having to construct content, which involves multiple skills, such as developing a thesis and sourcing relevant support for said thesis, students must also develop presentation skills, including the paralinguistic features highlighted above. These skills are of paramount importance to delivering a successful presentation. However, the challenge for course designers in incorporating these elements is not simply a case of focus and volition. Logistical constraints, including time and student numbers, caveat research recommendations on what should be covered within a presentation curriculum. Indeed, along with presentation skills, other academic skills (research, reading, critical thinking among others) also compete for focus, time and resources. Arguably, these constraints limit practice opportunities and feedback time, resulting in some students graduating from pre-university programmes without the 
required knowledge base, practice and experience in presenting. This is indeed an issue when considering the number of oral-based assessments students may have to complete on their subsequent degree programmes.

Potential solutions to the aforementioned constraints may be achieved through adopting CAL (Computer Assisted Learning) applications in which the students can practice, develop and receive feedback beyond the confines of the traditional classroom (e.g. Erbas \& Demirer, 2019; Makransky, Wismer \& Mayer, 2019; Song \& Lee, 2002; Zacharia, 2007). One such technology that could provide an ideal environment in which to foster the development of presentation skills beyond the classroom is Virtual Reality (VR). The potential of this technology lies in its immersive characteristics 'that aim to bring simulated real-life experiences, providing topography, movement and physics that offer the illusion of being there' (Smart, Cascio \& Paffendof, 2007). As well as being able to replicate the topographical features of a lecture theatre, a VR environment could also include avatars that serve as audience members able to display engagement with and provide feedback to a presenter immersed in a simulated real-life environment (see Figure 1). The argument here is that this technology has the potential to provide the called for greater focus on presentation skills, whilst also mitigating the logistical constraints highlighted above.

Figure 1. VR environment used in this study

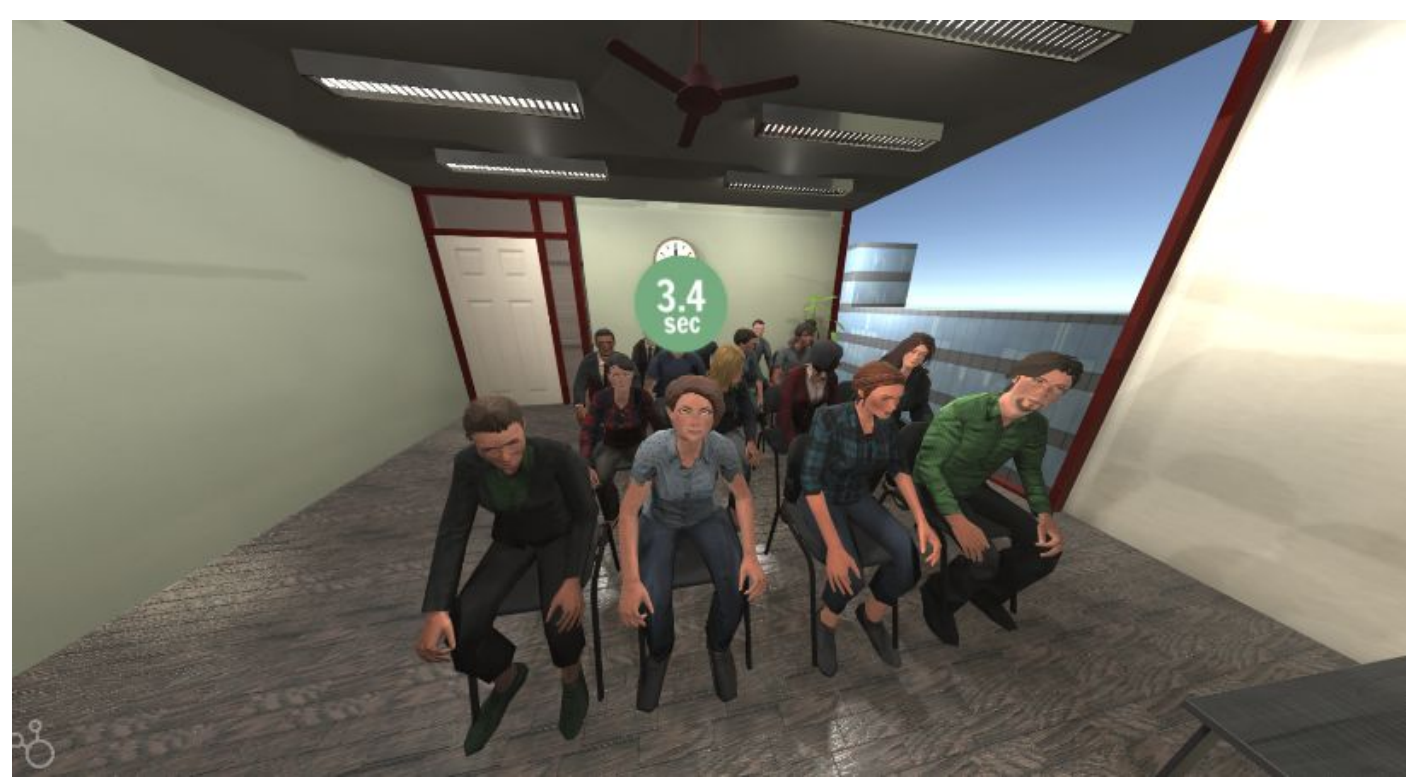




\section{Educational research in Virtual Reality (VR)}

There are few studies that have investigated the development of presentation skills within Virtual Reality. However, some that have been published focused on the potential impact of VR to decrease public speaking anxiety (e.g. Harris, Kemmerling \& North, 2005; Pertaub, Slater \& Barker, 2001). These studies demonstrated that students' anxiety when presenting can diminish through practising their presentations in front of a virtual audience as opposed to a real life audience. A number of other VR studies have suggested a positive impact on learning but these have tended to originate in the computer sciences and clinical sectors (e.g. Merchant et al., 2014; Opris, Pintea, García-Palacios, Botella, Szamosközi \& David, 2012; Sitzmann, 2011). However, these studies do present a number of guiding insights for the study presented in this paper, especially in terms of design and potential impact on learning outcomes.

Recent meta-analyses, based on a critical analysis of experimental and quasi-experimental studies, highlight that certain design characteristics of the VR learning environment are essential in facilitating learning. These characteristics relate to the immersive capabilities of VR environments and their potential to actively engage students in activities that can visually embody abstract concepts (e.g. relativity) and enhance learners' engagement (Dickey, 2003).

Central to this immersion is the type of environment and tasks within the environment. Merchant et al. (2014) explored three types of environments: games-based, simulation and virtual worlds. They observed that retention of learning appeared highest in games-based environments compared to simulation (e.g. delivering a presentation in a virtual hall) or virtual world environments (e.g. Second Life). While they did not speculate as to why, this could potentially be due to how the student orientates to the tasks at hand, the nature of the tasks and associated levels, and the inherent reward systems within a games-based environment. That is to say, an environment that includes clear goals, achievement levels and reward systems may further immerse the students in the learning (Merchant, Goetz, Cifuentes, Keeney-Kennicutt \& Davis, 2014).

Positive learning outcomes were also observed in simulation based environments. In this environment, the authors (Merchant et al., 2014) concluded that learning outcomes were more positive when the simulation served as a platform for practice and was embedded in a programme that delivered content in other instructional modes, such as the traditional classroom setting. This final point is important in the context of this study as the VR environment is a simulation and, 
therefore, based on this meta-data, the decision was taken to ensure the platform augmented the learning programme.

In sum, it appears that VR has the potential to: (1) reduce anxiety for students; and (2) have a positive impact on learning and the retention of learning, especially when integrating clear goals, objectives and achievement indicators. In this study, the environment can be considered a simulation. Therefore, factors such as the type of task, the perceived value from the user, and integration modes (whether the environment serves to augment or drive the learning) can be considered of significant importance. One area Merchant et al. (2014) highlighted as being underresearched within VR and having a clear impact on learning gains is feedback, both in terms of forms and timing (Merchant et al., 2014).

\section{Feedback within VR}

Feedback is considered as an essential component in the learning process (e.g. Hattie \& Timperley, 2007; Shute, 2008). Nevertheless, it must be stressed that feedback in and of itself does not guarantee learning. A student can be presented with feedback but fail to act on, see the relevance of, or interpret it in a manner that impacts learning. For feedback to lead to learning and impact performance, first and foremost, it must be intelligible and relatable in order to engage higher-order cognitive processes. These processes may be activated in a self-reflective stage. Therefore, a crucial step is providing feedback that promotes reflection, a stage that Quinton and Smallbone (2010) see as a vital part of the learning process. However, even with evidence of reflection, the student could still fail to understand how to enact change or simply decide that an adaptation in performance is not needed. What this highlights is that to assess whether feedback has impacted learning, one must first recognise the core processes involved. Moreover, one must also recognise that, while these processes may intuitively appear interconnected, they are separate, with one not necessarily triggering the other. For research, it is fundamental that any claim about the role of feedback in impacting learning be supported by evidence that shows a path between these three interconnected components: feedback, reflection, and adaptation in performance.

Two questions that have dominated the literature in feedback studies relate to timing and form. These studies have tended to focus on immediate versus delayed feedback. While some studies have suggested immediate feedback has a greater impact on learning (Dihoff, Brosvic, Epstein \& 
Cook, 2004; Epstein \& Brosvic, 2002), others have stressed that the timing and impact of feedback depends on the cognitive processes required (Clariana, Wagner \& Murphy, 2000). They suggested that feedback on items that require a greater degree of processing are more likely to favour delayed conditions. Support for this within CAL can be seen in a study by King et al. (2000). He suggested that immediate feedback was superior in influencing aspects that trigger automatic processing (e.g. adjust eye contact or use of voice), whereas delayed feedback was more effective for encouraging aspects of presentation skills that require deliberate and deeper processing (e.g. changing the length of an introduction in a presentation). In sum, choices about timing and form must take into account the cognitive load that will be placed on the individual in attending to, reflecting on and learning from the feedback.

Although frequently emphasized as a crucial factor in student learning (e.g. Hattie \& Timperley, 2007; Shute, 2008), research into the role of innovative technology for developing high quality feedback messages is scarce (Author, 2015; Merchant, Goetz, Cifuentes, KeeneyKennicutt, \& Davis, 2014). A recent review study published - in Educational Research Review on developing oral presentation skills (Author, 2015) stressed the importance of the type of feedback students receive, including teacher led feedback, peer assessment and self-assessment. An experimental follow-up study focused on the potential differential impact of feedback sources on developing students' presentation skills (Author, 2017a). This study demonstrated that students' development in presentation performance is significantly influenced by teachers compared to other commonly used feedback sources such as peers, peers guided by tutors and the self (Author, 2017a). This would suggest that CALL environments, whilst providing an alternative platform for learning, still require teachers to provide feedback, a point highlighted as a key logistical constraint within pre-university programmes above. However, if the VR environment were able to provide feedback at the level of the teacher and crucially be perceived by the student as such, then the need for a teacher in providing feedback could be reduced.

One such study that suggests this may be possible was conducted by Author and recently published in the journal Computers \& Education (Author, 2019). They showed students' presentation skills improved significantly, in both the group that practised in a virtual reality-based presentation task and a situation in which the student presented in front of a face-to-face audience. The crucial finding, however, was in how the feedback in these conditions was perceived by the participants. While the students emphasized the positive and constructive aspects of the feedback 
in the face-to-face situation, the feedback provided by the virtual reality system was appreciated because of its analytical and detailed character (Author, 2019). This suggests that VR systems can provide feedback that is perceived to be effective whilst also impacting learning outcomes. However, it should be highlighted that the presentation expert played a crucial role in both conditions: while experts observed and provided feedback to the students in the face-to-face situation, the teacher was also needed to interpret and explain the feedback reports generated by the VR system. However, if students were instructed on how to interpret the feedback or the feedback was coded and delivered in a more user-friendly, interpretive manner, then teachers or experts may not be needed.

Another area of promise within computer-mediated feedback is the potential of immediate feedback within the VR environment (Chollet, Wörtwein, Morency, Shapiro \& Scherer, 2015; King, Young \& Behnke, 2000). For example, the virtual audience could be used to provide immediate nonverbal feedback to participants based on their performance. This could be based on factors that the system was able to track and measure whilst the candidate was performing, and include non-verbal features, such as eye contact or prosodic features, such as pitch and pace. Essentially, if the presenter were to speak too quickly this could be made evident by the reactions of virtual avatars as audience members. Chollet et al. (2015) concluded that such immediate feedback could significantly increase students' performance. Potentially, this provision of automated immediate feedback could replace teacher-led feedback. However, whether immediate feedback has a similar impact to delayed feedback on learning outcomes needs to be explored further, especially in the context of virtual reality-based tasks aimed at developing students' presentation skills (Author, 2019). With this in mind, we will now turn to the focus of this study. 


\section{This study: objectives and methodology}

The central aim of this experimental study is to provide students, institutions and teachers with an alternative environment in which to deliver course content and practise presentation skills. Two skills served as the primary focus: eye contact and pace. Before conducting the study, a VR environment was created to mirror and immerse students in a life-like setting (see Figure 1). The setting was designed with consideration to core design principles mapped from literature above: (1) the environment is immersive and representative of a real-life setting; (2) the environment is responsive to the presenter's performance; (3) tasks encompass clear goals and objectives for the user; and (4) the environment is capable of providing immediate and delayed feedback which has an impact on learning outcomes.

The research goal was to explore whether:

A virtual reality-based presentation task with immediate feedback is as effective in terms of learning outcomes as a virtual reality-based presentation task with delayed feedback.

In pursuit of this goal, two research objectives were formulated based on gaps identified in the above literature:

1. to explore the differential impact of immediate versus delayed feedback on pre-university students' presentation skills within virtual reality.

2. to verify the extent to which pre-university students perceive such an innovative tool as valuable for fostering their presentation performance.

From a scientific perspective, these objectives are essential, since the potential differential impact between immediate and delayed feedback for developing presentation skills has not been researched within Virtual Reality (Author, 2019). In addition, findings could further inform debate on the efficacy of the type of feedback within presentation research (Author, 2015). Finally, by focusing on pre-university preparatory programmes, the findings are crucial to construct effective learning environments aimed at preparing students for oral assessments within tertiary education. 
From an educational practice perspective, the highlighted research focus is crucial, since many educators worldwide are aiming to develop effective learning environments to foster public speaking skills (Author, 2015; Chan, 2011). Moreover, in times of increasing pre-university student numbers and diminishing capacity for instructional time, virtual reality tools could help alleviate logistical constraints faced within conventional education. These developments could further support a shift towards personalised learning and provide crucial support for both learners and institutions (Author, 2019; Merchant et al., 2014).

\section{Methodology}

\subsection{Participants and context of the study}

The study was carried out with 22 pre-university students enrolled in a presentation skills course within a Dutch secondary education curriculum in the school year 2018. The programme had been designed to prepare students for the rigours of presenting within a university context. Almost two thirds of the students were male (14) and more than a third were female (8). The course included seven crucial design characteristics that a previous systematic review highlighted as requisites for a module in oral presentation skills (Author, 2015). These were: (1) clear learning objectives, (2) authentic presentation tasks, (3) behaviour modelling, (4) opportunity to practice presentation skills, (5) types of feedback, (6) peer assessment and (7) self-assessment. This study isolated item 5: types of feedback.

\subsection{Target features}

The target aspects addressed by this study were eye contact and pace, measured by speech rate. These two elements constitute core presentation skills, highlighted in the above review as potentially not receiving enough attention and focus within presentation curricula. These skills are also present within a validated oral presentation skills rubric that was previously adopted in presentation research (Author, 2017c). The primary aim was to measure the potential of the system to deliver feedback that would positively impact the students' performance in these two skills. Immediate feedback for eye contact was provided by the system through time icons that would appear if the speaker's eye contact began to linger. For example, if the student focused on their slides for more than five seconds, then an icon, projected in virtual reality, turned red, meaning that the student needed to adjust eye contact to re-engage with the virtual audience (see Figure 1). 
For pace, a similar icon would appear telling the speaker to slow down if their speech rate exceeded 160 words per minute. The timings are based on literature, which states that the optimal rate is 130 words per minute (in Dutch language) and that speakers should not exceed a speech rate of 160 words per minute or speak slower than 100 words per minute (Author, 2019). Students who received delayed feedback were not prompted within the system by icons. Instead, reports were generated by the system on both eye contact and pace and then interpreted and explained by an expert in a session lasting no longer than five minutes.

\subsection{Research design}

The research was carried out in three stages across a two-week period. During the first and third stages, students received a plenary in which they discussed presentation criteria in relation to the rubric. They then performed a 5-minute presentation in front of their peers on a self-selected topic related to the subject of Dutch language speaking. This was conducted in Dutch. In between these sessions, students practised their presentations in one of the two conditions within the VR environment. This session was scheduled so that there were exactly seven days between all three stages. In both VR conditions, students had to present for five minutes in front of a virtual audience, consisting of a classroom with students of a similar age (avatars). In the experimental condition, students presented in front of a virtual audience and received immediate feedback. The other students were grouped in the control condition, presenting in front of a virtual audience and receiving delayed feedback by a presentation expert after their performance.

The supplementary nature of the VR platform used in this research aligns with the recommendation above by Merchant et al. (2014) that a simulation based environment should serve to augment the curriculum, ideally by providing an environment in which to practise.

\subsection{Instructional conditions}

All participants were randomly designated to one the following feedback conditions: (1) virtual reality-based presentation task with immediate feedback $(n=8)$ and $(2)$ virtual reality-based presentation task with delayed feedback $(n=14)$. The presentation experts who provided the students with feedback had more than five years of experience teaching oral presentations skills at secondary level. Prior to this experiment, all experts were individually and plenary trained by the lead author. This training was aimed at facilitating the feedback processes in the particular 
conditions, focusing on: (1) the use of the Virtual Reality system for performing an individual presentation and (2) the procedure for the individual presenter about the length of the presentation and the provision of feedback. A presentation expert was also provided to instruct students on how to use the VR system. This involved training the students in how to mount the oculus and navigate the environment.

\subsection{Dependent variables and instruments}

Students' development was measured in pre- and post-test stages. Experiential feedback was also collected based on students' perceptions of (1) the value of the feedback provided and (2) performing the presentation task in virtual reality. This experiential component was measured through an evaluation questionnaire (post-test) after the last meeting of the course.

In the first and third stage of the research, students' presentation performances were assessed by adopting a rubric that was previously validated based on presentation literature (Author, 2015) and perceptions of presentation experts from differing domains and countries around the globe (Author, 2017c). The rubric contained the four main categories for presentation assessment: (1) content of the presentation, (2) structure of the presentation, (3) presentation delivery aspects (such as eye contact, use of voice, posture and gestures) and (4) interaction with the audience. Scores in these stages were calculated based on the average grades assigned for each of the presentation criteria by the experts. Scores relating to improvement in eye contact and pace were calculated and analysed separately and then compared to overall progress between the first and third stages of the research. The reliability coefficient for both the pre-test as well as the post-test revealed acceptable scores (Cronbach alpha $=.76$ and .77 respectively).

To measure experiential factors, all students completed an evaluation questionnaire (post-hoc only) after the last meeting of the course. The first part of the questionnaire contained four closed questions adopting a scale from one to five. These questions were designed to measure: (1) the extent to which the presentation task is perceived as realistic preparation for students' final presentation assessment, (2) the extent to which the presentation task motivates students to practice their presentation, (3) the value of the received feedback during or after the presentation task and (4) whether students would recommend the VR learning environment as an effective platform to practise presenting. Open questions were also included to measure: (1) to what extent students perceived the presentation task as valuable for improving their oral presentation skills and (2) 
whether students from both feedback groups perceived the virtual reality-based presentation task as a relevant replacement for a face-to-face presentation in their curriculum.

\subsection{Data analysis}

For tracing students' progress regarding oral presentation skills, paired-sample t-tests were adopted for both the experimental as well as the control condition. Further, repeated measurement ANOVAs were applied in order to analyse to what extent the development in presentation skills was dependent on the particular feedback group. Further, independent-sample t-tests were conducted to compare students' evaluation scores between the feedback conditions on the closed questions of the evaluation. Finally, the answers on the open questions were collected and then categorized using the inductive thematic analytical technique (Hayes, 2000), as recently applied in comparable studies focusing on the development of competencies in educational contexts (i.e., Popov, Noroozi, Barrett, Biemans, Teasley, Slof, \& Mulder, 2014).

\section{Results and discussion}

The objectives of the research were to 1) assess the differential impact of immediate versus delayed feedback on students' development and 2) verify the extent to which pre-university students perceive such an innovative tool as valuable for fostering their presentation performance. Sections 5.1 and 5.2 relate to the first aim and 5.3 explores the second.

\subsection{Students' progress in presentation skills}

The most significant finding was that students' overall oral presentation performance from the pre-test to post-test improved substantially $(t(21)=5.79 ; p<.01)$ (see Table 1). This improvement was observed across both conditions, immediate and delayed, without a difference in impact $(F(1,21)=3.52 ; p=.75)$. The overall improvement was reflected in the improvement observed in eye contact and pace, with, again, no significant differences between the two feedback groups $(F(1,21)=.32 ; p=.86)$. Interestingly, while the immediate feedback group made statistically identical improvement in both overall development, and eye contact and pace (1.32 and 1.31 respectively), the delayed group appeared to make greater gains in the latter: 0.71 overall versus 1.22. This could perhaps suggest that the delayed feedback was more successful than the immediate in effecting change in these specific aspects of performance. This would run counter to 
previous studies highlighted in the literature review that posited that immediate feedback would potentially be more effective in addressing elements that could be processed automatically and require less effortful processing. However, the difference is not statistically relevant on a probability reading, so is only presented as a tentative observation. It must also be noted that a longitudinal study may reveal more about the differential impact between the two, a point that is beyond this current study but suggested as a future direction within the conclusion.

The most important finding is that both groups made significant gains in both overall performance, and performance related criteria for which the VR environment was designed to develop: eye contact and pace. To assess whether this can be attributed to the feedback presented within the environment, this section will now turn to the qualitative, experiential data.

Table 1. Descriptive information of oral presentation skills for the two conditions

\begin{tabular}{|c|c|c|c|c|}
\hline Variables & Conditions & Pre-test & Post-test & $\begin{array}{l}\text { Mean } \\
\text { difference }\end{array}$ \\
\hline \multirow[t]{3}{*}{ Overall performance } & $\begin{array}{l}\text { 1. Immediate FB } \\
\text { Mean } \\
\text { Std. Deviation } \\
N\end{array}$ & $\begin{array}{l}6.11 \\
0.53 \\
22\end{array}$ & $\begin{array}{l}7.43 \\
0.89 \\
22\end{array}$ & $\begin{array}{l}1.32 * * \\
0.65 \\
22\end{array}$ \\
\hline & $\begin{array}{l}\text { 2. Delayed FB } \\
\text { Mean } \\
\text { Std. Deviation } \\
N \\
\end{array}$ & $\begin{array}{l}6.56 \\
1.26 \\
22 \\
\end{array}$ & $\begin{array}{l}7.27 \\
1.11 \\
22 \\
\end{array}$ & $\begin{array}{l}0.71^{* *} \\
0.76 \\
22 \\
\end{array}$ \\
\hline & $\begin{array}{l}\text { Total } \\
\text { Mean } \\
\text { Std. Deviation } \\
N\end{array}$ & $\begin{array}{l}6.39 \\
1.06 \\
22\end{array}$ & $\begin{array}{l}7.33 \\
1.02 \\
22\end{array}$ & $\begin{array}{l}0.94 * * \\
0.76 \\
22\end{array}$ \\
\hline \multirow[t]{3}{*}{ Eye contact and pace } & $\begin{array}{l}\text { 1. Immediate FB } \\
\text { Mean } \\
\text { Std. Deviation } \\
N\end{array}$ & $\begin{array}{l}6.00 \\
0.76 \\
22\end{array}$ & $\begin{array}{l}7.31 \\
1.03 \\
22\end{array}$ & $\begin{array}{l}1.31^{* *} \\
1.28 \\
22\end{array}$ \\
\hline & $\begin{array}{l}\text { 2. Delayed FB } \\
\text { Mean } \\
\text { Std. Deviation } \\
N\end{array}$ & $\begin{array}{l}6.32 \\
1.69 \\
22\end{array}$ & $\begin{array}{l}7.54 \\
1.35 \\
22\end{array}$ & $\begin{array}{l}1.22 * * \\
1.22 \\
22\end{array}$ \\
\hline & $\begin{array}{l}\text { Total } \\
\text { Mean } \\
\text { Std. Deviation } \\
N\end{array}$ & $\begin{array}{l}6.21 \\
1.41 \\
22\end{array}$ & $\begin{array}{l}7.46 \\
1.22 \\
22\end{array}$ & $\begin{array}{l}1.25^{* *} \\
1.21 \\
22\end{array}$ \\
\hline
\end{tabular}

Note: $*_{p}<0.05 ; *_{p}<0.01$. 


\subsection{Students' perceptions regarding received feedback}

As highlighted in the literature review, any claim about the role of feedback in impacting learning needs to be supported by evidence that shows a path between three interconnected components: feedback, reflection, and adaptation in performance. The observation that students across both feedback groups improved significantly does not serve as evidence that the feedback played a role in this development nor that the feedback led to reflection and engagement of cognitive processes in facilitating this development. To gauge whether this was the case, evidence of these processes from the students is required.

Table 2 shows students' qualitative responses to open questions within the questionnaire. These were coded thematically. Items four, five and six specifically relate to feedback. A total of eleven students across both feedback conditions made specific reference to the nature of the feedback provided within the VR environment. Within the delayed group, four commented on the relevancy of the detailed and analytical character of the feedback (item 4), and, within the immediate group, seven wrote that they appreciated the direct nature of the feedback and that it supported immediate behavioural change (item 5). This suggests a link between the feedback and improved scores. Perhaps more pertinent is that a total of six students across the two groups explicitly referenced that this feedback encouraged reflection and cited that this could have led to their improved performance (item 6). Although this is by no means conclusive nor does it capture the nuances of the students' subsequent uptake or cognitive processing of this feedback, it does present an explicit link between the feedback provided by the system which may have supported reflection and potentially performance. Of course, the link suggested and subsequent role of feedback in the improved performance can only be posited for just over half of the participants. However, the potential for such a link may still be plausible. Moreover, this also highlights the need for more qualitative data to explore this dimension.

In sum, participants across both groups made significant development in all presentation criteria across the two week programme $(t(21)=5.79 ; p<.01)$. This development was mirrored in eye contact and pace, the foci for this study and elements that the VR environment was specifically designed to develop. In terms of the differential impact of immediate versus delayed feedback, there was no significant statistical differentiation in rates of development. 
Table 2. Thematically coded responses to open questions within questionnaire

\begin{tabular}{|c|c|c|}
\hline \multirow[t]{2}{*}{ Answers } & $\begin{array}{l}\text { Imme- } \\
\text { diate FB }\end{array}$ & $\begin{array}{l}\text { Delayed } \\
\text { FB }\end{array}$ \\
\hline & $\begin{array}{l}\text { Number of } \\
\text { students }\end{array}$ & $\begin{array}{l}\text { Number of } \\
\text { students }\end{array}$ \\
\hline $\begin{array}{l}\text { 1. Relevant, because practicing is good } \\
\text { for developing presentation skills }\end{array}$ & 5 & 6 \\
\hline $\begin{array}{l}\text { 2. Relevant, because of the realism of the } \\
\text { VR-environment }\end{array}$ & 2 & 6 \\
\hline $\begin{array}{l}\text { 3. Relevant, because of the entertaining } \\
\text { factor which motives the presenter }\end{array}$ & 3 & 6 \\
\hline $\begin{array}{l}\text { 4. Relevant, because of the detailed and } \\
\text { analytical feedback }\end{array}$ & 0 & 4 \\
\hline $\begin{array}{l}\text { 5. Relevant, because of the direct } \\
\text { character of feedback which supports } \\
\text { to improve behaviour immediately }\end{array}$ & 7 & 0 \\
\hline $\begin{array}{l}\text { 6. Relevant, because the feedback } \\
\text { encourages reflection skills which } \\
\text { could lead to improved presentation } \\
\text { skills }\end{array}$ & 3 & 3 \\
\hline $\begin{array}{l}\text { 7. Relevant, because of getting familiar } \\
\text { with the VR-technique }\end{array}$ & 0 & 2 \\
\hline $\begin{array}{l}\text { 8. Not relevant, because the activity was } \\
\text { not realistic }\end{array}$ & 0 & 1 \\
\hline
\end{tabular}

\subsection{Students' perceptions of the VR environment as an effective platform to foster presentation performance}

The qualitative data in Table 2 reveals that eight students explicitly mentioned that the VR environment served as a realistic environment in which to practise their presentations, with only one student stating that the environment did not serve as a realistic setting in which to practise presenting. Nine mentioned that the entertainment value of the platform motivated them. From the data collected from the closed questions (see Table 3), we can see that participants rated the platform highly (above 4 out of a possible 5 in all cases) in terms of the task being realistic and motivating. This rating also applied to whether they would recommend the platform to a fellow student. Across the two data sets it is interesting to note that the delayed group appeared to rate the environment higher than the immediate group. This was especially the case in the qualitative open-questions where almost twice as many participants within the delayed group referenced the environment as relevant becomes of its realistic and motivating qualities. This may suggest that the presence of an expert to reflect on performance and experience after being in the environment is a key factor in associating the task as having real-world relevance. For the group that received 
immediate feedback within the environment no such reflective element was facilitated by an expert. this could be an important psychological factor to consider within future studies, especially when exploring the transference of skills from the virtual plain to real-world application.

In sum, the students responses suggest they held positive perceptions of the platform as an environment in which to develop their presentation skills. The high-ratings here would support this, but again caution must be taken in interpreting these, especially considering the potential for the novelty factor. That is, students were asked to rate the environment after a single use. Repeated exposure may have tamed enthusiastic responses.

Table 3. Responses to closed questions on a scale of 1-5

\begin{tabular}{llll}
\hline Evaluation aspects & $\begin{array}{l}\text { Imme- } \\
\text { diate FB }\end{array}$ & $\begin{array}{l}\text { Delayed } \\
\text { FB }\end{array}$ & $\begin{array}{l}\text { Differences } \\
\text { between } \\
\text { conditions }\end{array}$ \\
\hline $\begin{array}{l}\text { 1) This presentation task was a realistic } \\
\text { preparation for my final presentation. }\end{array}$ & & \\
Mean & 4.25 & 4.64 & 0.34 \\
Std. Deviation & 0.46 & 0.63 & 0.60 \\
$N$ & 8 & 14 & 22 \\
\hline 2) This presentation task motivates me to & & \\
practice my presentation. & 4.25 & 4.57 & 0.32 \\
Mean & 0.87 & 0.76 & 0.80 \\
Std. Deviation & 8 & 14 & 22 \\
$N$ & & & \\
\hline 3) The feedback that I received during or & & & \\
after this presentation task was valuable. & 4.50 & 4.57 & 0.07 \\
Mean & 0.76 & 0.65 & 0.67 \\
Std. Deviation & 8 & 14 & 22 \\
$N$ & & & \\
\hline 4) I would recommend other students to fulfil & & \\
this presentation task in VR. & 4.75 & 4.57 & 0.18 \\
Mean & 0.46 & 0.65 & 0.58 \\
Std. Deviation & 8 & 14 & 22 \\
$N$ & & & \\
\hline
\end{tabular}




\subsection{Conclusions and discussion}

This experimental study focused on the potential differential impact of immediate versus delayed feedback on developing pre-university students' oral presentation skills within virtual reality. Results demonstrated a significant increase in public speaking skills across the two feedback groups. This may suggest that immediate feedback is as effective as delayed. However, it must be noted that this conclusion was only in respect to eye contact and pace. There is no evidence here to suggest that this would pertain to feedback across all presentation criteria. While there appears to be some qualitative support for attributing learning gains to the feedback provided by the system, there is not sufficient data to show that students who referenced that the feedback triggered reflection actually made a conscious change in presentation performance based on this. This could have perhaps been achieved by recording the students within the environment and incorporating more extensive reflection after the students had finished the task. It is recommended that future researchers perhaps incorporate such practise within their methodology. One further suggestion is that developers try to incorporate both types of feedback and perhaps differentiate along a paralinguistic-content spectrum, with the latter provided via delayed feedback. This recommendation is in reference to the above literature review that highlighted that delayed conditions may be more appropriate for feedback that requires deeper cognitive processing. As a caveat, we recommend that the number of presentation delivery aspects provided within each type of feedback should be limited in order to prevent cognitive overload (Author, 2017b). What is not clear from this study is whether the feedback had a longitudinal impact on performance, so we recommend this as a focus for future studies.

Several limitations remain that are important to keep in mind when interpreting the results of this study. First, the small sample size should be emphasized as a limitation. Although previous studies demonstrated the value of experimental studies with limited sample sizes (e.g. Author, 2019; Biemans \& Simons, 1996), follow-up studies should increase the number of participants in order to strengthen the power of the study. Second, measuring presentation delivery, as an important component of presentation skills, was restricted to only the following two sub criteria: eye contact and speech rate. However, presentation delivery aspects also contain sub-criteria such as speech frequency, speech volume and the use of fillers. Therefore, incorporating other relevant sub-criteria of the presentation delivery will automatically increase the validity of such a study. This, however, will be contingent on technological developments within VR. Currently, we are 
working to develop voice recognition software that can transcribe a presentation. It is hoped that this could be used to highlight to the speaker pronunciation issues (e.g. if a word is not recognised), and other phonological components of speech.

While the programme used in this study still requires further development, we believe that the results show that VR platforms could play an integral role in addressing limitations faced by institutions, teachers and students, especially within university preparatory programmes that teach students how to present. In this study, delayed feedback still required an expert to interpret the data; however, by translating the quantitative data into more intelligible, qualitative feedback messages within the system (as previously explored by Author, 2019), the need for experts and the time constraints this requires would be resolved. As a result, teachers, as presentation experts, could pay more attention to both (1) designing presentation curricula in which virtual reality-based tasks could be integrated and (2) coaching their students.

\section{Ethical statement}

In order to guarantee the integrity of the experiment, the following actions were taken: (1) adopting the guidelines for research integrity expressed in the Netherlands Code of Conduct for Scientific Practice, (2) obtaining informed consent from program directors, course leaders, teachers and participating students and (3) anonymizing all personal data regarding student characteristics according to the policy of data management within the University of Applied Sciences Utrecht. No funding was provided for the study. 


\section{References}

Author (2015).

Author (2017a).

Author (2017b).

Author (2017c).

Author (2019).

Biemans, H. J., \& Simons, P. R. J. (1996). CONTACT-2: A computer-assisted instructional strategy for promoting conceptual change. Instructional Science, 24(2), 157-176. https://doi.org/10.1007/BF00120487

Bower, M., Cavanagh, M., Moloney, R., \& Dao, M. (2011). Developing communication competence using an online Video Reflection system: pre-service teachers' experiences. AsiaPacific Journal of Teacher Education, 311-326. https://doi.org/10.1080/1359866X.2011.614685

Chan, V. (2011). Teaching oral communication in undergraduate science: Are we doing enough and doing it right? Journal Of Learning Design, 4(3), 71-79. https://files.eric.ed.gov/fulltext/EJ940652.pdf

Chollet, M., Wörtwein, T., Morency, L. P., Shapiro, A., \& Scherer, S. (2015). Exploring feedback strategies to improve public speaking: an interactive virtual audience framework. In Proceedings of the 2015 ACM International Joint Conference on Pervasive and Ubiquitous Computing (pp. 1143-1154). ACM. doi: 10.1145/2750858.2806060

Clariana, R. B., Wagner, D., \& Murphy, L. C. R. (2000). Applying a connectionist description of feedback timing. Educational Technology Research and Development, 48(3), 5-22. https://doi.org/10.1007/BF02319855

De Grez, L., Valcke, M., \& Roozen, I. (2009). The impact of an innovative instructional intervention on the acquisition of oral presentation skills in higher education. Computers \& Education, 53(1), 112-120. https://doi.org/10.1016/j.compedu.2009.01.005

Dickey, M. D. (2003). Teaching in 3D: Pedagogical affordances and constraints of 3D virtual worlds for synchronous distance learning. Distance education, 24(1), 105-121. https://doi.org/10.1080/01587910303047 
Dihoff, R. E., Brosvic, G. M., Epstein, M. L., \& Cook, M. J. (2004). Provision of feedback during preparation for academic testing: Learning is enhanced by immediate but not delayed feedback. The Psychological Record, 54(2), 207-231. https://doi.org/10.1007/BF03395471

Epstein, M. L., \& Brosvic, G. M. (2002). Students prefer the immediate feedback assessment technique. Psychological reports, 90(3_suppl), 1136-1138. https://doi.org/10.2466/pr0.2002.90.3c.1136

Erbas, C., \& Demirer, V. (2019). The effects of augmented reality on students' academic achievement and motivation in a biology course. Journal of Computer Assisted Learning, 19. DOI: $10.1111 /$ jcal.12350

Harris, S. R., Kemmerling, R. L., \& North, M. M. (2002). Brief virtual reality therapy for public speaking anxiety. Cyberpsychology \& behavior, 5(6), 543-550. https://doi.org/10.1089/109493102321018187

Hattie, J., \& Timperley, H. (2007). The power of feedback. Review of Educational Research, 77(1), 81-112. https://doi.org/10.3102/003465430298487

Hayes, N. (2000). Doing psychological research. Buckingham: Open University Press.

Hinton, J. S., \& Kramer, M. W. (1998). The impact of self-directed videotape feedback on students' self-reported levels of communication competence and apprehension. Communication Education, 47(2), 151-161. https://doi.org/10.1080/03634529809379119

Januin, J., \& Stephen, J. (2015). Exploring discourse competence elements in EAP class presentations through document and ethnographic analyses. Procedia-Social and Behavioral Sciences, 208, 157-166. https://doi.org/10.1016/j.sbspro.2015.11.192

Kerby, D., \& Romine, J. (2009). Develop oral presentation skills through accounting curriculum design and course-embedded assessment. Journal of Education for Business, 85(3), 172- 179. https://doi.org/10.1080/08832320903252389

King, P., Young, M., \& Behnke, R. (2000). Public speaking performance improvement as a function of information processing in immediate and delayed feedback interventions. Communication Education, 49(4), 365-374. https://doi.org/10.1080/03634520009379224

Makransky, G., Wismer, P., \& Mayer, R. E. (2019). A gender matching effect in learning with pedagogical agents in an immersive virtual reality science simulation. Journal of Computer Assisted Learning, 35(3), 349-358. 
Merchant, Z., Goetz, E. T., Cifuentes, L., Keeney-Kennicutt, W., \& Davis, T. J. (2014). Effectiveness of virtual reality-based instruction on students' learning outcomes in K-12 and higher education: A meta-analysis. Computers \& Education, 70, 29-40. https://doi.org/10.1016/j.compedu.2013.07.033

Opris, D., Pintea, S., García-Palacios, A., Botella, C., Szamosközi, Ş., \& David, D. (2012). Virtual reality exposure therapy in anxiety disorders: a quantitative meta-analysis. Depression and anxiety, 29(2), 85-93. https://doi.org/10.1002/da.20910

Pertaub, D-P., Slater, M., \& Barker, C. (2001). An experiment on fear of public speaking in virtual reality. In J. D. Westwood, H M. Hoffman, G. T. Mogel \& D. Stredney (Eds.) Medicine meets virtual ( reality $\quad$ (pp. 372-378). https://www.researchgate.net/profile/Mel_Slater/publication/12017692_An_experiment_on_ fear_of_public_speaking_in_virtual_reality/links/00b495219d7573d4fa000000.pdf

Popov, V., Noroozi, O., Barrett, J. B., Biemans, H., Teasley, S. D., Slof, B., \& Mulder, M. (2014). Perceptions and experiences of, and outcomes for, university students in culturally diversified dyads in a computer-supported collaborative learning environment. Computers in Human Behavior, 32, 186-200. https://doi.org/10.1016/j.chb.2013.12.008

Quinton, S., \& Smallbone, T. (2010). Feeding forward: using feedback to promote student reflection and learning-a teaching model. Innovations in Education and Teaching International, 47(1), 125-135. https://doi.org/10.1080/14703290903525911

Reitmeier, C. A., \& Vrchota, D. A. (2009). Self-assessment of oral communication presentations in food science and nutrition. Journal of Food Science Education, 8(4), 88-92. https://doi.org/10.1111/j.1541-4329.2009.00080.x

Robinson, R. (2015). Pecha Kucha: How to improve students' presentation skills. European Conference on Language Learning, Brighton, United Kingdom, 1-5. http://papers.iafor.org/wp-content/uploads/papers/ecl12015/ECLL2015_17575.pdf

Shute, V. J. (2008). Focus on formative feedback. Review of Educational Research, 78(1), 153189. https://doi.org/10.3102/0034654307313795

Sitzmann, T. (2011). A meta-analytic examination of the instructional effectiveness of computer-based simulation games. Personnel psychology, 64(2), 489-528. https://doi.org/10.1111/j.1744-6570.2011.01190.x 
Smart, J., Cascio, J. \& Paffendof, J. (2007). Metaverse roadmap: pathways to the 3D web. Retrieved, May 10, 2008, from <http://www.metaverseroadmap.org/overview>. http://www.metaverseroadmap.org/overview

Smith, C. M., \& Sodano, T. M. (2011). Integrating lecture capture as a teaching strategy to improve student presentation skills through self-assessment. Active Learning in Higher Education, 12(3), 151-162. https://doi.org/10.1177/1469787411415082

Song, K. S., \& Lee, W. Y. (2002). A virtual reality application for geometry classes. Journal of Computer Assisted Learning, 18(2), 149-156. https://doi.org/10.1046/j.02664909.2001.00222.x

Zacharia, Z. C. (2007). Comparing and combining real and virtual experimentation: an effort to enhance students' conceptual understanding of electric circuits. Journal of Computer Assisted Learning, 23(2), 120-132. doi: 10.1111/j.1365-2729.2006.00215.x 


\section{Practitioner Notes}

What is already known about this topic

- Pre-university students are often underprepared to deliver academic presentations, a key means of assessment.

- Virtual Reality (VR) applications can facilitate much needed practice and provide both immediate and delayed feedback to students.

- Previous studies have suggested that both immediate and delayed feedback can impact learning outcomes and effect development.

- The nature and medium of feedback delivery has yielded variable results in relation to development.

What this paper adds:

- Computer mediated immediate feedback appears as effective as delayed feedback delivered by an expert in terms of impacting presentation performance.

- Experiential data shows that students perceive a VR platform as a viable alternative to face-to-face practice.

Implications for practice/or policy

- To better prepare pre-university students, Institutions could adopt VR platforms to augment presentation modules.

- Computer mediated immediate feedback may be as effective as face-to-face delayed feedback in effecting change in students' presentation performance. 